\title{
Emotion dysregulation in hypochondriasis and depression
}

\author{
Josef Bailer ${ }^{1} \quad$ Michael Witthöft $^{2} \quad$ Maja Erkic $^{1} \quad$ Daniela Mier $^{1}$ (c)
}

${ }^{1}$ Department of Clinical Psychology, Central Institute of Mental Health, Medical Faculty Mannheim, University Heidelberg, Mannheim, Germany

${ }^{2}$ Department of Clinical Psychology, Psychotherapy and Experimental Psychopathology, University of Mainz, Mainz, Germany

\section{Correspondence}

Dr. Daniela Mier, Department of Clinical Psychology, Central Institute of Mental Health, Mannheim, Square J 5; 68159 Mannheim, Germany.

Email: daniela.mier@zi-mannheim.de
Background: The aim of this study was to explore whether certain aspects of emotion dysregulation (i.e., facets of alexithymia and rumination) are more closely linked to hypochondriasis than to depression and vice versa.

Methods: Nineteen patients with hypochondriasis (HYP), 33 patients with depression, and 52 healthy control participants completed the Toronto Alexithymia Scale, the Response Styles Questionnaire, and additional symptom and illness behaviour scales. A clinical interview was used to establish DSM-IV diagnoses and to exclude all cases with more than one axis I diagnosis.

Results: Depression patients reported more difficulties describing feelings and more symptom- and self-focused rumination than both HYP patients and healthy individuals, whereas HYP patients differed only from healthy individuals in regard to more difficulties in identifying feelings and more symptom-focused rumination. Multiple regression analyses, including all assessed facets of emotion dysregulation, showed that the degree of somatoform features (somatic symptoms, health anxiety, and illness behaviour) was specifically predicted by higher difficulties in identifying feelings scores, whereas depressive symptom levels were specifically predicted by higher rumination scores.

Conclusions: Specific associations were found between difficulties in identifying feelings and key features of HYP, whereas depression was linked to a more generalized pattern of emotion regulation deficits.

\section{Key Practitioner Message}

- Emotion dysregulation can be found in hypochondriasis and depression

- Difficulties in identifying own feelings are specifically linked to somatic symptoms, health anxiety, and illness behaviour, whereas a more generalized pattern of emotion dysregulation is found in relation to depression

- Further research is needed to investigate whether the effectiveness of current treatments for depression, hypochondriasis, health anxiety, and related disorders could be improved by additional emotion regulation interventions

\section{KEYWORDS}

affect regulation, alexithymia, depression, hypochondriasis, rumination
The role of emotion dysregulation in the pathogenesis and maintenance of a variety of mental disorders is widely accepted (Aldao, Nolen-Hoeksema, \& Schweizer, 2010; Sheppes, Suri, \& Gross, 2015). While depression is linked to emotion dysregulation in general and rumination specifically, only recently, there is growing awareness for deficits in emotion regulation for explaining and treating patients with somatic symptom disorders, including hypochondriasis. However, until now, empirical assessments of emotion regulation in hypochondriasis are still limited, and have been mainly conducted in college populations varying in health anxiety (Fergus \& Valentiner, 2010; Görgen, Hiller, \& Witthöft, 2014; Marcus, Hughes, \& Arnau, 2008). The present study aimed at investigating the specificity of two types of emotion dysregulation: alexithymia and rumination, for hypochondriasis and depression. 
Alexithymia can be defined as an emotion dysregulation trait, because it is characterized by difficulties in identifying, discriminating, describing, and communicating one's own feelings, as well as externally oriented thinking rather than reflection on inner experience (Sifneos, 1988). Alexithymia is considered to be an important risk factor for the development of mental disorders, especially for psychosomatic and somatoform disorders (Taylor, 2000), and has been associated with increased somatic symptom reports (De Gucht \& Heiser, 2003; Tominaga, Choi, Nagoshi, Wada, \& Fukui, 2014). It is supposed that alexithymia is linked to somatization by the way of focusing on or amplifying the physical sensations associated with emotional arousal, or by incorrectly attributing the physical sensations as somatic symptoms or signs of disease (Lumley, Stettner, \& Wehmer, 1996).

Several methods have been developed to assess alexithymia, including structured interviews, self-report scales, observer measures, and projective tests (Cosci, 2012). Currently, one of the most commonly used psychometric instruments for measuring alexithymia is the 20-item Toronto Alexithymia Scale (TAS-20) (Bagby, Taylor, \& Parker, 1994b). This well-validated self-report scale (Lumley, Neely, \& Burger, 2007; Taylor \& Bagby, 2004) consists of three subscales: difficulty identifying feelings (DIF), difficulty describing feelings (DDF), and externally oriented thinking (EOT). Recent studies focussing on specific associations between the various facets of the TAS-20 and different psychopathologies found that especially the DIF scale was strongly related to somatic symptoms (Huber, Suman, Biasi, \& Carli, 2009; Lumley et al., 2005; Mattila et al., 2008; Mattila et al., 2009; Shibata et al., 2014), whereas medium relationships where observed between depression and both the DIF and the DDF scale (Harding, Murphy, \& Mezulis, 2015).

Further studies with mixed findings investigated the mutual relationship between alexithymia and negative affect to explain somatic symptoms. A number of studies have demonstrated that both concepts are independent predictors of somatic symptom reporting (Deary, Scott, \& Wilson, 1997; Wearden, Cook, \& Vaughan-Jones, 2003). In addition, in one general population study, positive associations between alexithymia and somatic symptom reporting were found independently of somatic diseases, depression, and anxiety, as well as confounding sociodemographic variables (Mattila et al., 2008). Yet, in another general population study, this association became nonsignificant after controlling for negative affect, suggesting that negative feelings or depression may mediate the association between alexithymia and somatic symptoms (Shibata et al., 2014).

Ruminative coping in response to negative feelings and symptoms of depression (Just \& Alloy, 1997; Nolen-Hoeksema, Larson, \& Grayson, 1999; Nolen-Hoeksema, Stice, Wade, \& Bohon, 2007) or to somatic complaints (Marcus et al., 2008) represents a further maladaptive emotion regulation strategy that has been closely linked to depression (Abela \& Hankin, 2011). Habitual rumination about depressed mood has been shown to predict the development of depression and has been linked to the severity and course of depressive symptoms and psychosocial functioning (Abela \& Hankin, 2011; Just \& Alloy, 1997; Kuehner \& Huffziger, 2012; Nolen-Hoeksema et al., 1999). In contrast, distractive coping, defined as actively turning one's attention away from negative feelings and thoughts on to pleasant or neutral thoughts and actions, predicted a more benign course of depression
(Huffziger, Reinhard, \& Kuehner, 2009). In addition, rumination has been associated with anxiety and has been presented as a mediator between symptoms of anxiety and depression (McLaughlin \& Nolen-Hoeksema, 2011).

In the context of hypochondriasis, a relationship between the level of health anxiety and rumination has been demonstrated in college samples (Görgen et al., 2014; Marcus et al., 2008), suggesting that rumination may play a central role in the development of hypochondriasis (Marcus et al., 2008). Importantly, the results of Görgen and colleagues suggest that rumination directly contributes to health anxiety and that this effect is not mediated by depressive symptoms (Görgen et al., 2014). In addition, a recent study revealed the maintaining effects of rumination on health anxiety in college students (Gautreau et al., 2015). However, studies investigating rumination in patients with hypochondriasis are missing.

An open question is the specificity of alexithymia and rumination for hypochondriasis and depression. While the construct of alexithymia has been developed in response to the symptom pattern of psychosomatic patients (Sifneos, 1988), the term rumination has been adapted to the cognitive domain to describe typical thought patterns of depressive patients in response to depressive mood (Nolen-Hoeksema, 1991). However, these days, there is evidence suggesting enhanced levels of alexithymia and rumination in both disorders (Abela \& Hankin, 2011; Görgen et al., 2014; Harding et al., 2015; Mattila et al., 2008). Using a large sample of patients with a medical disease, a subtype of depression characterized by high levels of alexithymia and functional somatic symptoms has been identified (Guidi et al., 2011). In agreement, several studies showed a mutual relationship between negative affect, alexithymia, depression, and somatic symptoms (Harding et al., 2015; Lipsanen, Saarijarvi, \& Lauerma, 2004; Saariaho, Saariaho, Mattila, Karukivi, \& Joukamaa, 2013; Yalug et al., 2010; Zunhammer, Eberle, Eichhammer, \& Busch, 2013).

Due to the current state of literature that suggests rumination, as well as alexithymia in both, depression and hypochondriasis, studies are needed that shed light on the specificity of deficits in different facets of emotion dysregulation for hypochondriasis and depression. Further, due to the currently limited number of studies that directly assess emotion dysregulation in hypochondriasis, more studies are needed that increase our knowledge of emotion dysregulation characteristics in hypochondriasis.

Thus, the aim of the present study was to explore whether facets of alexithymia and rumination are specifically linked to hypochondriasis and depression. Because categorical diagnoses based on clinical interviews (e.g., depression and hypochondriasis) and continuous self-report measures of symptom strength (based on questionnaires) convey partly overlapping but yet distinct information (i.e., existence of a diagnosis vs. level of symptom strength), we aimed at assessing the relations of alexithymia and rumination to both levels of information (i.e., categorical diagnoses as well as continuous measures of symptom strength). We compared indicators of emotion dysregulation among cases with hypochondriasis, cases with a current depressive disorder, and healthy individuals. We hypothesized that hypochondriasis and depression would both be associated with more difficulties in identifying and describing feelings and more habitual rumination 
(compared to healthy controls). In addition, we expected that levels of rumination would be highest in depression. Given the proposed key role of alexithymia for somatoform disorders and somatic symptom distress (e.g., (Taylor, 2000)), it was hypothesized that the diagnosis of hypochondriasis as well as continuous measures of symptom distress, health anxiety, and illness behaviour would be particularly strongly related to high DIF scores.

\section{METHODS}

\subsection{Design and procedure}

Originally, 162 participants from a larger multilevel study on health anxiety (Bailer et al., 2014; Bailer et al., 2016; Kerstner et al., 2015; Witthöft et al., 2016) were included in this investigation: 58 participants with hypochondriasis, 52 participants with depression, and 52 healthy controls. Patients were recruited from a cognitive behaviour therapy outpatient unit at the Central Institute of Mental Health, Mannheim, Germany. Healthy individuals were recruited by advertisements published in local newspapers and on the web page of the Central Institute of Mental Health.

All participants completed a set of screening questionnaires related to health anxiety and depression, and a check list for diseases and current medication, prior to study inclusion (Bailer et al., 2016). Diagnosis of hypochondriasis as well as all other current axis I diagnoses were made according to the DSM-IV criteria (American Psychiatric Association, 2000) using a comprehensive clinical interview for mental disorders (SCID-I) (First, Spitzer, Gibbon, \& Williams, 1997). General exclusion criteria were the following: age below 18 and above 65 years, life time diagnoses of psychotic disorders, substance use disorders, organic brain disease or organic mental disorders, presence of a current somatic illness that could account for the hypochondriacal complaints, and inadequate command of German.

Not surprisingly, both of the original patient groups were characterized by high rates of comorbid mental disorders. In accordance with previous findings (Abramowitz, Olatunji, \& Deacon, 2007; Barsky, Wyshak, \& Klerman, 1992; Noyes et al., 1994; Olatunji, Deacon, \& Abramowitz, 2009), high rates of anxiety disorders (62.1\%; mainly panic disorders) and depression (32.8\%; mainly major depression) were found in the original hypochondriasis group, and $40.4 \%$ of the original depression group had an additional anxiety disorder. As the primary aim of the current study was to strictly test for disorder-specific associations with alexithymia and rumination, all patients with comorbid mood and anxiety disorders were excluded from the clinical groups. Thus, the final study sample was composed of the following diagnostic groups: patients ( $n=19$; hypochondriasis group) suffering from hypochondriasis only, patients ( $n=33$; depression group) suffering from depression only (either a major depressive episode $[n=21]$ or dysthymia $[n=3]$ or double depression $[n=9])$, and a healthy comparison group $(n=52)$ without any clinically significant axis I disorders.

Ethical approval was obtained from the Medical Ethics Committee of the Medical Faculty Mannheim at the University of Heidelberg, Germany. Participants were informed about study procedure and purposes and provided written informed consent prior to being enrolled in the study.

\subsection{Measures}

\subsubsection{Structured clinical interview}

In all three groups, mental disorders were assessed in face-to-face interviews with the Structured Interview for DSM-IV disorders (SCID-I) (First et al., 1997). The clinical interviews were conducted by six experienced, specially trained, and closely supervised clinical psychologists.

\subsubsection{Symptom measures}

Health anxiety was assessed with the Short Health Anxiety Inventory (SHAI). The SHAI contains 14 items in multiple-choice format that probe the range of health anxiety irrespective of the physical health status (Salkovskis, Rimes, Warwick, \& Clark, 2002). The Screening for Somatoform Symptoms (SOMS) (Rief, Hiller, \& Heuser, 1997) was used to assess 33 somatic symptoms relevant for the diagnosis of somatization disorder according to DSM-IV. Finally, the Patient Health Questionnaire (PHQ) (Spitzer, Williams, \& Kroenke, 1999) was used to assess current depressive (PHQ-9) symptoms. These well-validated symptom scales had good reliability (SHAl: $\alpha=.97$, SOMS: $\alpha=.89$, PHQ-9: $a=.92$ ) in our original sample of the present study.

\subsubsection{Illness behaviour}

The 25-items total score of the Scale for the Assessment of Illness Behaviour (SAIB) (Rief, Ihle, \& Pilger, 2003; Rief, Martin, Klaiberg, \& Brahler, 2005) was used to assess various aspects of illness behaviour such as verification of diagnosis, expression of symptoms, need for medication/treatment, consequences of illness, and body scanning. Higher SAIB scores indicate higher illness behaviour. In our original sample, the coefficient a for the total scale was .95.

\subsubsection{Emotion dysregulation}

To assess various aspects of alexithymia, we used the German version (Bach, Bach, de Zwaan, Serim, \& Bohmer, 1996) of the TAS-20 (Bagby, Parker, \& Taylor, 1994a; Bagby et al., 1994b). The widely used TAS-20 consists of three subscales, measuring DIF (seven items), DDF (five items), and EOT (eight items), respectively. In our original sample, reliability estimates for the total scale (20 items, Cronbach's $a=.84$ ) and two subscales (DIF: $a=.84$; DDF: $a=.79$ ) were high, but considerably lower for the EOT subscale $(\alpha=.56)$. The poor reliability and questionable validity of the EOT subscale has been noted in previous studies (Kooiman, Spinhoven, \& Trijsburg, 2002; Lumley et al., 2005; Taylor, Bagby, \& Parker, 2003; Wearden et al., 2003). Furthermore, no significant group differences were found for the EOT subscale in the present sample. Given these findings, further analyses addressing alexithymia are only reported for the DIF and the DDF subscales and the TAS-20 total score.

In addition, the 23-item German version of the Response Styles Questionnaire (RSQ-D) was used to assess habitual aspects of rumination and distraction in response to depressed mood (Kuehner, Huffziger, \& Nolen-Hoeksema, 2007). The reliable and well-validated RSQ-D (Buerger \& Kuehner, 2007; Kuehner \& Huffziger, 2012; 
Kuehner et al., 2007) consists of three scales: symptom-focused rumination (SYFR; ruminations about one's depressive symptoms), self-focused rumination (SEFR; ruminations about one's self), and distraction (turning one's attention to neutral or pleasant thoughts and actions). In our original sample, a coefficient for these scales was $.89, .86$, and .85 .

\subsection{Statistical analyses}

All data were analysed with SPSS Version 22 (SPSS Inc., Chicago, III., USA). Groups were compared using analyses of variance (ANOVA) and multivariate analyses of variance for continuous variables, followed by Bonferroni adjusted post hoc comparisons between specific groups. Effect sizes are reported as partial $\eta^{2}$ values $\left(\eta^{2} \geq .01\right.$ small effect; $\eta^{2} \geq .06$ medium effect; $\eta^{2} \geq .14$ large effect) and Cohen's $d(d=0.2$ small effect; $d=0.5$ medium effect; $d \geq 0.8$ large effect). For categorical variables, the chi-square test was used. Multiple linear regression analyses were performed to predict continuous criterion variables. The variance inflation factor was calculated to test for multicollinearity among the predictor variables and was within normal ranges for all predictors.

\section{RESULTS}

\subsection{Sample characteristics}

Descriptive data about sociodemographic and psychopathological characteristics of all three groups are presented in Table 1. The groups were matched for age, sex, and education. Patients with hypochondriasis showed significantly higher levels of health anxiety, somatic symptoms, and illness behaviour than both patients with depression and healthy controls.

\subsection{Group differences in levels of alexithymia and rumination}

With regard to between-group differences in the five emotion dysregulation subscales (DIF, DDF, and the three RSQ-D subscales), a multivariate ANOVA revealed a large significant multivariate group effect (Wilks Lambda: $F_{(10,194)}=25.03, p<.001, \eta_{p}{ }^{2}=.47$ ), and subsequent ANOVAs indicated that the three diagnostic groups did differ significantly on all subscales (Table 2). Pairwise post hoc tests, Bonferroni adjusted for multiple comparisons, showed that depression patients reported significantly more DDF and more SYFR and SEFR than both hypochondriasis patients (DDF: $p=.006$; SYFR: $p<.001$; SEFR: $p<.001$ ) and healthy individuals (DDF $p<.001$; SYFR: $p<.001$; SEFR $p<.001)$, and more DIF $(p<.001)$ than healthy individuals. Furthermore, hypochondriasis patients reported more DIF $(p<.001)$ and more SYFR $(p<.001)$ than healthy controls. No significant group differences were found between hypochondriasis patients and depression patients on the DIF scale $(p=1.00)$. Finally, compared to the healthy group, both clinical groups scored significantly lower on the only subscale (distraction subscale) assessing functional emotion regulation strategies (hypochondriasis: $p<.001$; depression: $p<.001$ ).

Concerning the TAS-20 total score, using an ANOVA and Bonferroni adjusted pairwise post hoc comparisons, the healthy group scored significantly lower than both clinical groups (hypochondriasis: $p=.018$; depression: $p<.001$ ). The two clinical groups did not differ significantly $(p=.301)$.

\subsection{Syndrome-specific associations}

Finally, we conducted a series of multiple regression analyses among the total sample to explore whether certain facets of alexithymia and rumination are more closely linked to main features of hypochondriasis and health anxiety (i.e., somatic symptom report, health anxiety, and illness behaviour) than to current levels of depressive symptoms and vice versa. In these analyses, all five emotion dysregulation variables were entered simultaneously into the regression model as potential predictors to test their unique association with key characteristics of hypochondriasis and health anxiety (SOMS, SHAI, and SAIB scores) and current depression (PHQ-9 scores). The results of these analyses are summarized in Table 3. Specific associations were found for higher DIF and lower DDF scores with all somatoform features, whereas the intensity of current depressive symptoms was significantly predicted by higher SYFR and SEFR and lower distraction subscale scores. However, because the according zero-order

TABLE 1 Sample characteristics

\begin{tabular}{|c|c|c|c|c|c|}
\hline Variable & $\begin{array}{l}1 \\
\text { HYP group } \\
(n=19)\end{array}$ & $\begin{array}{c}2 \\
\text { Depression group } \\
(n=33)\end{array}$ & $\begin{array}{c}3 \\
\text { Healthy group } \\
(n=52)\end{array}$ & $\begin{array}{c}\text { ANOVA } / \chi^{2} \text {-test } \\
F / \chi^{2} \text {-value }\end{array}$ & $\begin{array}{l}\text { Post hoc group } \\
\text { comparisons }\end{array}$ \\
\hline Age in years $(M \pm S D)$ & $43.5 \pm 12.4$ & $42.8 \pm 11.9$ & $42.1 \pm 12.9$ & 1.0 & - \\
\hline Gender (\% female) & 57.9 & 48.5 & 59.6 & 1.1 & - \\
\hline Education ( $\% \geq 12$ years) & 78.9 & 69.7 & 69.2 & 0.7 & - \\
\hline Health anxiety (SHAl; $M \pm S D$ ) & $28.5 \pm 4.8$ & $9.3 \pm 2.8$ & $5.8 \pm 2.8$ & $346.7^{* * *}$ & $1>2>3$ \\
\hline Depressive symptoms (PHQ-9) & $7.8 \pm 3.9$ & $17.2 \pm 4.1$ & $1.7 \pm 2.0$ & $237.9^{* * *}$ & $2>1>3$ \\
\hline Somatoform symptoms (SOMS; $M \pm S D$ ) & $4.8 \pm 3.4$ & $1.7 \pm 2.0$ & $0.4 \pm 1.2$ & $34.3^{* * *}$ & $1>2,3$ \\
\hline Illness behaviour (SAIB sum score; $M \pm S D$ ) & $59.8 \pm 9.9$ & $39.5 \pm 8.4$ & $37.1 \pm 6.6$ & $60.4^{* * *}$ & $1>2,3$ \\
\hline
\end{tabular}

Note. HYP = hypochondriasis; SHAI = Short Health Anxiety Inventory; PHQ-9 = Patient Health Questionnaire; SOMS = Screening for Somatoform Symptoms; SAIB = Scale for the Assessment of Illness Behaviour.

Significant values are presented in bold. - means no post-hoc test, because the 3-group comparisons were not significant.

${ }^{* * *} p \leq .001$. 
TABLE 2 Comparison of TAS-20 and RSQ-D scores (means \pm SD) between diagnostic groups

\begin{tabular}{|c|c|c|c|c|c|c|c|c|c|}
\hline Variable & $\begin{array}{l}1 \\
\text { HYP group } \\
(n=19)\end{array}$ & $\begin{array}{c}2 \\
\begin{array}{c}\text { Depression group } \\
(n=33)\end{array}\end{array}$ & $\begin{array}{c}3 \\
\text { Healthy group } \\
(n=52)\end{array}$ & $\begin{array}{l}\text { ANOVA } \\
\text { F-value }\end{array}$ & $\begin{array}{l}\text { Effect } \\
\text { size } \eta_{p}{ }^{2}\end{array}$ & $\begin{array}{l}\text { Post hoc group } \\
\text { comparisons }\end{array}$ & $\begin{array}{c}1 \text { vs } 2 \\
d\end{array}$ & $\begin{array}{c}1 \text { vs } 3 \\
d\end{array}$ & $\begin{array}{c}2 \text { vs } 3 \\
d\end{array}$ \\
\hline \multicolumn{10}{|l|}{ TAS-20 } \\
\hline Total score & $45.7 \pm 9.4$ & $50.5 \pm 12.4$ & $38.0 \pm 8.8$ & $15.9^{* * *}$ & .24 & $1,2>3$ & .45 & .84 & 1.16 \\
\hline DIF & $16.5 \pm 4.1$ & $16.8 \pm 5.8$ & $9.6 \pm 2.9$ & $36.5^{* * *}$ & .42 & $1,2>3$ & .06 & 1.94 & 1.57 \\
\hline DDF & $11.3 \pm 4.0$ & $14.5 \pm 4.8$ & $9.8 \pm 3.4$ & $14.1^{* * *}$ & .22 & $2>1,3$ & .72 & .40 & 1.13 \\
\hline \multicolumn{10}{|l|}{ RSQ-D } \\
\hline SYFR & $16.6 \pm 5.4$ & $21.6 \pm 4.7$ & $11.9 \pm 3.6$ & $53.4^{* * *}$ & .50 & $2>1>3$ & .98 & 1.02 & 2.32 \\
\hline SEFR & $12.5 \pm 4.6$ & $17.4 \pm 4.6$ & $10.4 \pm 4.1$ & $26.5^{* * *}$ & .34 & $2>1,3$ & 1.06 & .48 & 1.61 \\
\hline DIS & $15.1 \pm 4.0$ & $14.2 \pm 3.7$ & $20.2 \pm 4.5$ & $25.0^{* * *}$ & .33 & $3>1,2$ & .23 & 1.20 & 1.45 \\
\hline
\end{tabular}

Note. HYP = hypochondriasis; TAS-20 = Toronto Alexithymia Scale; DIF = difficulties in identifying feelings subscale; DDF = difficulties in describing feelings subscale; RSQ-D = German version of the Response Styles Questionnaire; SYFR = symptom-focused rumination subscale; SEFR = self-focused rumination subscale; DIS = distraction subscale; $d$ = effect size Cohen's $d$.

Significant values are presented in bold.

${ }^{* * *} p \leq .001$.

correlations were not significant, these negative associations seem to represent suppression effects. The variance (adjusted $R^{2}$ ) explained by the total model with all predictors varied between $14 \%$ (SAIB) and 68\% (PHQ-9).

\section{DISCUSSION}

The aim of this study was to investigate the specificity of different types of emotion dysregulation, particularly alexithymia and rumination, for hypochondriasis and depression. Our results from the comparison of the patient groups with the healthy control sample replicate previous findings of emotion dysregulation in mental disorders (Aldao et al., 2010) and add to the literature on emotion dysregulation in hypochondriasis and depression (Berking, Wirtz,
Svaldi, \& Hofmann, 2014; Fergus \& Valentiner, 2010; Görgen et al., 2014; Millgram, Joormann, Huppert, \& Tamir, 2015).

Both clinical groups reported higher levels of DDF and more SYFR than healthy controls. Furthermore, healthy individuals reported more distractive coping than patients-which can be seen as an adaptive emotion regulation strategy, because distractive coping has been linked to lower levels of depression (Huffziger et al., 2009; Li, DiGiuseppe, \& Froh, 2006). These results suggest that both patient groups do not only present with an increase in dysfunctional emotion regulation strategies, but also less engagement in functional strategies, while the usage of dysfunctional emotion regulation strategies seems to be of even higher relevance for the occurrence of psychopathology than the lack of adaptive strategies (Aldao \& Nolen-Hoeksema, 2010).

To our knowledge, this is the first study directly comparing trait emotion dysregulation in depression and hypochondriasis. Our main

TABLE 3 Predicting somatization (SOMS, SHAI, SAIB scores) and depressive symptom severity (PHQ-9) by emotion dysregulation variables using multiple linear regression analyses

\begin{tabular}{|c|c|c|c|c|c|c|c|c|}
\hline \multirow[b]{2}{*}{ Predictors } & \multicolumn{2}{|c|}{$\begin{array}{c}\text { Somatic symptoms } \\
\text { (SOMS) }\end{array}$} & \multicolumn{2}{|c|}{$\begin{array}{c}\text { Health } \\
\text { anxiety (SHAI) }\end{array}$} & \multicolumn{2}{|c|}{$\begin{array}{l}\text { Illness behaviour } \\
\text { (SAIB total score) }\end{array}$} & \multicolumn{2}{|c|}{$\begin{array}{c}\text { Depressive } \\
\text { symptoms (PHQ-9) }\end{array}$} \\
\hline & $r$ & $\beta$ & $r$ & $\beta$ & $r$ & $\beta$ & $r$ & $\beta$ \\
\hline DIF & $.40^{* * *}$ & $.60^{* * *}$ & $.32^{* * *}$ & $.52^{* * *}$ & $.35^{* * *}$ & $.47^{* * *}$ & $.59^{* * *}$ & .10 \\
\hline DDF & .07 & $-.34^{* * a}$ & .00 & $-.41^{* * * a}$ & .07 & $-.25^{* a}$ & $.45^{* * *}$ & .06 \\
\hline SYFR & $26^{* *}$ & .06 & $.21^{*}$ & -.02 & $.29^{* * *}$ & .17 & $.76^{* * *}$ & $.47^{* * *}$ \\
\hline SEFR & .13 & -.08 & .13 & -.01 & .14 & -.09 & $.65^{* * *}$ & $.21^{* *}$ \\
\hline DIS & $-.21^{*}$ & -.09 & $-26^{* *}$ & -.19 & -.15 & .02 & $-.53^{* * *}$ & $-.20^{* *}$ \\
\hline Total variance explained adj $R^{2}$ & \multicolumn{2}{|c|}{$.19^{* * *}$} & \multicolumn{2}{|c|}{$.17^{* * *}$} & \multicolumn{2}{|c|}{$.14^{* * *}$} & \multicolumn{2}{|c|}{$.68^{* * *}$} \\
\hline
\end{tabular}

Note. SOMS = Screening for Somatoform Symptoms; SHAI = Short Health Anxiety Inventory; SAIB = Scale for the Assessment of IIIness Behaviour; PHQ9 = Patient Health Questionnaire; DIF = difficulties in identifying feelings subscale; DDF = difficulties in describing feelings subscale; SYFR = symptomfocused rumination subscale; SEFR = self-focused rumination subscale; DIS = distraction subscale; $r=$ zero-order correlations; $\beta=$ standardized beta coefficients.

Sample size: $n=104$. Variance inflation factors were within normal ranges: 1.37-2.38.

Significant values are presented in bold.

${ }^{a}$ As the respective zero-order correlation coefficients are non-significant, the shown significant negative associations in the regression analyses are most likely attributable to the existence of suppressor effects.

${ }^{* * *} p \leq .001$.

${ }^{* *} p \leq .01$.

${ }^{*} p \leq .05$. 
finding is that patients with depression reported more difficulties in describing feelings and habitual SYFR and SEFR in response to depressed mood, while patients with hypochondriasis reported more difficulties in identifying feelings and more SYFR, but only in comparison to healthy individuals.

Importantly, multiple regression analyses, using continuous disorder-related symptom scores, revealed a much clearer pattern of results with difficulty in identifying feelings being specifically linked to main features of hypochondriasis (i.e., health anxiety, somatic symptom report, and illness behaviour), whereas SYFR and SEFR being more closely linked to depressive symptoms. These findings support the specificity of a possible deficit in identifying feelings in patients with hypochondriasis. However, they also raise the question whether difficulties identifying feelings are specifically related to hypochondriasis, or whether they represent a rather general characteristic of somatization. Fergus and colleagues (Fergus \& Valentiner, 2010) showed in a college sample that disease phobia is predicted by somatic amplification, but that disease conviction is predicted by emotion regulation deficits. Hence, further studies may be of interest disentangling different forms of emotion dysregulation, and their impact on health anxiety versus somatisation.

These results suggest that different emotion regulation strategies might represent central and specific targets for psychotherapeutic interventions in hypochondriasis and depression. While in general emotion regulation trainings seem warranted for both groups, patients with hypochondriasis seem to be especially in need to improve the ability to identify their own feelings. Recent studies already suggested the relevance to improve the ability to identify feelings in order to reduce somatic complaints (Shibata et al., 2014). This finding is in line with the positive association of the different indices of somatization with DIF, but not DDF. It is assumed that patients' somatic symptoms arise by somatic amplification, that is, a dysfunctional focussing and thus reinforcement of bodily sensations (Barsky, Goodson, Lane, \& Cleary, 1988). For hypochondriasis, it has been proposed that patients additionally (mis-)attribute these somatic sensations as a sign of a disease (Bailer et al., 2013; Barsky, Coeytaux, Sarnie, \& Cleary, 1993). The importance of difficulties identifying own feelings for hypochondriasis has recently been supported by a study showing an association between alexithymia, interoceptive awareness, and health anxiety in a nonclinical population (Longarzo et al., 2015), pointing to the importance to improve hypochondriasis patients' ability to decipher their bodily feelings. Thus, interventions supporting patients to recognize and understand the effects of emotions on body processes might be helpful to augment cognitive-behavioural therapy in hypochondriasis. Besides a classical cognitive-behavioural therapy approach with psychoeducation aiming at a profound knowledge of physiological correlates of emotions, as well as situation analyses to understand emotion body symptom cascades, mindfulness- and acceptance-based strategies seem promising regarding the improvement of emotional awareness, identification and differentiation of emotions (Baer, Smith, \& Allen, 2004; Hill \& Updegraff, 2012), and might even facilitate adaptive emotion regulation (Diedrich, Hofmann, Cuijpers, \& Berking, 2016; Erisman \& Roemer, 2010). In this context Kleinstäuber, Gottschalk, Berking, Rau, and Rief (2016), recently conducted a multi-centre study investigating the beneficial effect of enriching cognitive-behavioural therapy for patients with somatic symptom disorder (including patients that would have been diagnosed with hypochondriasis according to DSM-IV) with emotion regulation strategies focusing on mindfulness- and acceptance-based techniques. The results of this ongoing study will give further evidence for the effectiveness of emotion regulation strategies in the treatment of somatic symptom disorders.

These findings may also serve to complement and specify existing theoretical models of health anxiety (e.g., (Warwick \& Salkovskis, 1990; Williams, 2004): Presumably, in addition to exaggerated bodyand symptom-focused attention allocation (Witthöft et al., 2013; Witthöft et al., 2016), the observed difficulties in identifying feelings might foster the occurrence and salience of subjectively unexplainable bodily sensations (in the sense of somatic aspects of unidentifiable emotions). In this regard, the observed deficits in identifying feelings would be causally linked to the tendency to excessively ruminate about bodily sensations (including processes of misinterpretation and catastrophizing), thereby increasing body-focused attention, somatosensory amplification, and the probability of somatosensory false alarms due to biased interoception (Krautwurst, Gerlach, Gomille, Hiller, \& Witthöft, 2014; Krautwurst, Gerlach, \& Witthöft, 2016). Experimental studies are needed to further test the exact mechanism by which the observed difficulties in identifying feelings and SYFR in parallel to other cognitive biases contribute to pathological health anxiety.

While we cannot draw general conclusions about necessary emotion regulation interventions in depression, because we did not assess the classic strategies, such as reappraisal and suppression, our results support the importance of alexithymia and rumination in depression. Aldao et al. (2010) found strong associations between depression and rumination, but only moderate associations between depression and reappraisal. Interestingly, Millgram and colleagues (Millgram et al., 2015) demonstrated that patients with depression do not only show more dysfunctional emotion regulation strategies, but also focus their emotion regulation on circumstances that might maintain their depressive mood. Thus, besides general emotion regulation trainings, rumination might be an important target for psychotherapeutic interventions in depression, suggesting therapeutic interventions as used for the treatment of generalized anxiety disorder to help depressed patients not only to work on depressive convictions, but also to help them disengaging from worrying processes. Beyond the importance to address rumination in depression therapy, alexithymia seems to be of high importance. As reported by Guidi and colleagues, and as shown in our sample, alexithymia presents with high prevalence in depression (Guidi et al., 2011). Hence, further studies are needed that assess an even broader range of emotion dysregulation in depression to explore whether the deficits can be reduced to a circumscribed number of core impairments that can be specifically targeted in therapy.

Certain limitations of the study should be noted. First, emotion dysregulation was assessed by two self-report scales, which may be subject to recall bias. Especially, the observed associations between depression and nearly all facets of emotion dysregulation strategies could be caused by a mood-associated recall bias. This seems especially important for alexithymia, because the TAS has been 
criticized to merely reflect negative affect in depression (Marchesi, Ossola, Tonna, \& De Panfilis, 2014). Future studies should not only assess depressive symptoms, but also measures of affect (e.g., with the Positive and Negative Affect Schedule (Watson, Clark, \& Tellegen, 1988)) to investigate the link between current mood and self-reported emotion dysregulation. Second, the generalizability of the findings is limited by the selection criteria of the study and the sample sizes of the diagnostic groups, which are large enough to test for large but not for small to medium group differences. Further, our restriction of the sample to those patients with a single diagnosis limits power of statistical analyses. However, it has the advantage that the exclusion of any comorbidity allows a strict test for examining the specificity of alexithymia and rumination for hypochondriasis versus depression. Moreover, we focussed on only two forms of emotion dysregulation, that is, alexithymia and rumination, but not on adaptive emotion regulation strategies, such as reappraisal. This is limiting the generalizability of our results for general emotion regulation deficits in our patient groups. Third, all diagnoses made in this study are based on clinical interviews for DSM-IV disorders. This is a point of discussion, because the former diagnosis of hypochondriasis was actually deleted in the DSM-5 (American Psychiatric Association, 2013): Individuals with pathological health anxiety now receive the diagnosis "somatic symptom disorder" if they suffer from one or more additional somatic symptoms, or the diagnosis "illness anxiety disorder," if they do not experience distressing somatic symptoms. We tried to compensate for this limitation by using disorder-specific symptom scales in order to assess central facets of somatic symptom disorder (e.g., somatic symptoms and illness behaviour) and illness anxiety disorder (e.g., health anxiety) instead of merely relying on binary diagnostic categories. However, it remains open for future research whether the reported associations remain stable in patient groups diagnosed according to the DSM-5. Further, we agree with other researchers in the view that the DSM-5 conceptualization of the former category of somatoform disorders suffers from several flaws and that a more detailed and transdiagnostic focus and conceptualization of specific aspects (e.g., different types of illness behaviour) is needed. A good example of such an elaborate alternative approach represents the Diagnostic Criteria for Psychosomatic Research (Cosci \& Fava, 2016; Fava et al., 1995). Finally, our findings are cross-sectional and correlational only and cannot be used to infer causality. Thus, our findings warrant replication in prospective studies to clarify the role of emotion dysregulation as possible causal risk factor for the development, course, and outcome of depression and hypochondriasis.

To summarize, our results suggest that disorder-specific types of emotion dysregulation exist for health anxiety and depression. While both, rumination and alexithymia occur in depression and hypochondriasis, DIF is specifically linked to the main features of hypochondriasis (e.g., health anxiety, illness behaviour, and somatic symptoms), while depression is linked to a broader range of emotion dysregulation. Our findings can be used to guide the development of new emotionfocused treatments. Because the role of emotion regulation has been largely neglected in hypochondriasis, specific emotion regulation trainings may represent promising adjuncts of existing disorderspecific cognitive-behavioural interventions.

\section{ACKNOWLEDGEMENTS}

Parts of this study were funded by the German Research Foundation (DFG, BA 1597/5). The sponsors had no role in the design, execution, interpretation, or decision to publish any aspect of the project. We are grateful to Dr. Tobias Kerstner, Dr. Julia Ofer, Dr. Iris Wollgarten, and Dr. Stefania Utzeri for their helpful assistance with data collection.

\section{CONFLICT OF INTEREST}

All authors declare that they have no conflicts of interest.

\section{REFERENCES}

Abela, J. R., \& Hankin, B. L. (2011). Rumination as a vulnerability factor to depression during the transition from early to middle adolescence: $A$ multiwave longitudinal study. Journal of Abnormal Psychology, 120(2), 259-271. https://doi.org/10.1037/a0022796

Abramowitz, J. S., Olatunji, B. O., \& Deacon, B. J. (2007). Health anxiety, hypochondriasis, and the anxiety disorders. Behavior Therapy, 38(1), 86-94. https://doi.org/10.1016/j.beth.2006.05.001

Aldao, A., \& Nolen-Hoeksema, S. (2010). Specificity of cognitive emotion regulation strategies: A transdiagnostic examination. Behaviour Research and Therapy, 48(10), 974-983. https://doi.org/10.1016/j. brat.2010.06.002.

Aldao, A., Nolen-Hoeksema, S., \& Schweizer, S. (2010). Emotion-regulation strategies across psychopathology: A meta-analytic review. Clinical Psychology Review, 30(2), 217-237. https://doi.org/10.1016/j. cpr.2009.11.004

American Psychiatric Association (2000). Diagnostic and statistical manual of mental disorders, fourth edition, text revision (DSM-IV-TR). Washington, DC: American Psychiatric Association.

American Psychiatric Association (2013). Diagnostic and statistical manual of mental disorders (5th ed.). Arlington: American Psychiatric Publishing.

Bach, M., Bach, D., de Zwaan, M., Serim, M., \& Bohmer, F. (1996). Validation of the German version of the 20-item Toronto alexithymia scale in normal persons and psychiatric patients. Psychotherapie, Psychosomatik, Medizinische Psychologie, 46(1), 23-28.

Baer, R. A., Smith, G. T., \& Allen, K. B. (2004). Assessment of mindfulness by self-report: The Kentucky inventory of mindfulness skills. Assessment, 11(3), 191-206. https://doi.org/10.1177/1073191104268029

Bagby, R. M., Parker, J. D., \& Taylor, G. J. (1994a). The twenty-item Toronto alexithymia scale-I. Item selection and cross-validation of the factor structure. Journal of Psychosomatic Research, 38(1), 23-32.

Bagby, R. M., Taylor, G. J., \& Parker, J. D. (1994b). The twenty-item Toronto alexithymia scale-II. Convergent, discriminant, and concurrent validity. Journal of Psychosomatic Research, 38(1), 33-40.

Bailer, J., Müller, T., Witthöft, M., Diener, C., Mier, D., Ofer, J., \& Rist, F. (2013). Symptomattributionsstile bei Hypochondrie. Psychotherapeut, 58(6), 552-559.

Bailer, J., Witthoft, M., Wagner, H., Mier, D., Diener, C., \& Rist, F. (2014). Childhood maltreatment is associated with depression but not with hypochondriasis in later life. Journal of Psychosomatic Research, 77(2), 104-108. https://doi.org/10.1016/j.jpsychores.2014.06.004

Bailer, J., Kerstner, T., Witthöft, M., Diener, C., Mier, D., \& Rist, F. (2016). Health anxiety and hypochondriasis in the light of DSM-5. Anxiety, Stress, 29(2), 219-239. https://doi.org/10.1080/10615806.2015.1036243

Barsky, A. J., Goodson, J. D., Lane, R. S., \& Cleary, P. D. (1988). The amplification of somatic symptoms. Psychosomatic Medicine, 50(5), 510-519.

Barsky, A. J., Wyshak, G., \& Klerman, G. L. (1992). Psychiatric comorbidity in DSM-III-R hypochondriasis. Archives of General Psychiatry, 49(2), 101-108.

Barsky, A. J., Coeytaux, R. R., Sarnie, M. K., \& Cleary, P. D. (1993). Hypochondriacal patients' beliefs about good health. The American Journal of Psychiatry, 150(7), 1085-1089. https://doi.org/10.1176/ ajp.150.7.1085 
Berking, M., Wirtz, C. M., Svaldi, J., \& Hofmann, S. G. (2014). Emotion regulation predicts symptoms of depression over five years. Behaviour Research and Therapy, 57, 13-20. https://doi.org/10.1016/j. brat.2014.03.003

Buerger, C., \& Kuehner, C. (2007). Coping styles in response to depressed mood. Factor structure and psychometric properties of the German version of the response styles questionnaire (RSQ). Zeitschrift $f, 36(1)$, $36-45$.

Cosci, F. (2012). Assessment of personality in psychosomatic medicine: Current concepts. Advances in Psychosomatic Medicine, 32, 133-159. https://doi.org/10.1159/000330014

Cosci, F., \& Fava, G. A. (2016). The clinical inadequacy of the DSM-5 classification of somatic symptom and related disorders: An alternative trans-diagnostic model. CNS Spectrums, 21(4), 310-317. https://doi. org/10.1017/S1092852915000760

De Gucht, V., \& Heiser, W. (2003). Alexithymia and somatisation: Quantitative review of the literature. Journal of Psychosomatic Research, 54(5), 425-434.

Deary, I. J., Scott, S., \& Wilson, J. A. (1997). Neuroticism, alexithymia and medically unexplained symptoms. Personality and Individual Differences, 22(4), 551-564

Diedrich, A., Hofmann, S. G., Cuijpers, P., \& Berking, M. (2016). Selfcompassion enhances the efficacy of explicit cognitive reappraisal as an emotion regulation strategy in individuals with major depressive disorder. Behaviour Research and Therapy, 82, 1-10. https://doi.org/ 10.1016/j.brat.2016.04.003

Erisman, S. M., \& Roemer, L. (2010). A preliminary investigation of the effects of experimentally induced mindfulness on emotional responding to film clips. Emotion, 10(1), 72-82. https://doi.org/10.1037/a0017162

Fava, G. A., Freyberger, H. J., Bech, P., Christodoulou, G., Sensky, T., Theorell, T., \& Wise, T. N. (1995). Diagnostic criteria for use in psychosomatic research. Psychotherapy and Psychosomatics, 63(1), 1-8.

Fergus, T. A., \& Valentiner, D. P. (2010). Disease phobia and disease conviction are separate dimensions underlying hypochondriasis. Journal of Behavior Therapy and Experimental Psychiatry, 41(4), 438-444. https://doi.org/10.1016/j.jbtep.2010.05.002

First, M. B., Spitzer, R. L., Gibbon, M., \& Williams, J. B. W. (1997). Structured clinical interview for DSM-IV axis I disorders : SCID-I. Washington, DC: American Psychiatric Press.

Gautreau, C. M., Sherry, S. B., Sherry, D. L., Birnie, K. A., Mackinnon, S. P., \& Stewart, S. H. (2015). Does catastrophizing of bodily sensations maintain health-related anxiety? A 14-day daily diary study with longitudinal follow-up. Behavioural and Cognitive Psychotherapy, 43(4), 502-512. https://doi.org/10.1017/S1352465814000150

Görgen, S. M., Hiller, W., \& Witthöft, M. (2014). Health anxiety, cognitive coping, and emotion regulation: A latent variable approach. International Journal of Behavioral Medicine, 21(2), 364-374. https://doi.org/ 10.1007/s12529-013-9297-y

Guidi, J., Fava, G. A., Picardi, A., Porcelli, P., Bellomo, A., Grandi, S., .. Sonino, N. (2011). Subtyping depression in the medically ill by cluster analysis. Journal of Affective Disorders, 132(3), 383-388. https://doi. org/10.1016/j.jad.2011.03.004

Harding, K. A., Murphy, K. M., \& Mezulis, A. (2015). Cognitive mechanisms reciprocally transmit vulnerability between depressive and somatic symptoms. Depression Research and Treatment, 2015, 250594. https://doi.org/10.1155/2015/250594

Hill, C. L., \& Updegraff, J. A. (2012). Mindfulness and its relationship to emotional regulation. Emotion, 12(1), 81-90. https://doi.org/10.1037/ a0026355

Huber, A., Suman, A. L., Biasi, G., \& Carli, G. (2009). Alexithymia in fibromyalgia syndrome: Associations with ongoing pain, experimental pain sensitivity and illness behavior. Journal of Psychosomatic Research, 66(5), 425-433. https://doi.org/10.1016/j.jpsychores.2008.11.009

Huffziger, S., Reinhard, I., \& Kuehner, C. (2009). A longitudinal study of rumination and distraction in formerly depressed inpatients and community controls. Journal of Abnormal Psychology, 118(4), 746-756. https://doi.org/10.1037/a0016946

Just, N., \& Alloy, L. B. (1997). The response styles theory of depression: Tests and an extension of the theory. Journal of Abnormal Psychology, 106(2), 221-229.

Kerstner, T., Witthöft, M., Mier, D., Diener, C., Rist, F., \& Bailer, J. (2015). A diary-based modification of symptom attributions in pathological health anxiety: Effects on symptom report and cognitive biases. Journal of Consulting and Clinical Psychology, 83(3), 578-589. https://doi.org/ 10.1037/a0039056

Kleinstäuber, M., Gottschalk, J., Berking, M., Rau, J., \& Rief, W. (2016). Enriching cognitive behavior therapy with emotion regulation training for patients with multiple medically unexplained symptoms (ENCERT): Design and implementation of a multicenter, randomized, activecontrolled trial. Contemporary Clinical Trials, 47, 54-63.

Kooiman, C. G., Spinhoven, P., \& Trijsburg, R. W. (2002). The assessment of alexithymia: A critical review of the literature and a psychometric study of the Toronto alexithymia scale-20. Journal of Psychosomatic Research, 53(6), 1083-1090.

Krautwurst, S., Gerlach, A. L., Gomille, L., Hiller, W., \& Witthöft, M. (2014). Health anxiety-an indicator of higher interoceptive sensitivity? Journal of Behavior Therapy and Experimental Psychiatry, 45(2), 303-309. https://doi.org/10.1016/j.jbtep.2014.02.001

Krautwurst, S., Gerlach, A. L., \& Witthöft, M. (2016). Interoception in pathological health anxiety. Journal of Abnormal Psychology, 125(8), 1179-1184. https://doi.org/10.1037/abn0000210

Kuehner, C., \& Huffziger, S. (2012). Response styles to depressed mood affect the long-term course of psychosocial functioning in depressed patients. 136(3), 627-633.

Kuehner, C., Huffziger, S., \& Nolen-Hoeksema, S. (2007). Response styles questionnaire-German version (RSQ-D).

Li, C. E., DiGiuseppe, R., \& Froh, J. (2006). The roles of sex, gender, and coping in adolescent depression. Adolescence, 41(163), 409-415.

Lipsanen, T., Saarijarvi, S., \& Lauerma, H. (2004). Exploring the relations between depression, somatization, dissociation and alexithymiaoverlapping or independent constructs? Psychopathology, 37(4), 200-206. https://doi.org/10.1159/000080132

Longarzo, M., D'Olimpio, F., Chiavazzo, A., Santangelo, G., Trojano, L., \& Grossi, D. (2015). The relationships between interoception and alexithymic trait. The self-awareness questionnaire in healthy subjects. Frontiers in Psychology, 6, 1149. https://doi.org/10.3389/ fpsyg.2015.01149

Lumley, M. A., Stettner, L., \& Wehmer, F. (1996). How are alexithymia and physical illness linked? A review and critique of pathways. Journal of Psychosomatic Research, 41(6), 505-518.

Lumley, M. A., Radcliffe, A. M., Macklem, D. J., Mosley-Williams, A., Leisen, J. C., Huffman, J. L., D'Souza, P. J., Gillis, M. E., Meyer, T. M., Kraft, C. A., \& Rapport, L. J. (2005). Alexithymia and pain in three chronic pain samples: Comparing Caucasians and African Americans. Pain Medicine, 6(3), 251-261. https://doi.org/10.1111/j.1526-4637.2005.05036.x

Lumley, M. A., Neely, L. C., \& Burger, A. J. (2007). The assessment of alexithymia in medical settings: Implications for understanding and treating health problems. Journal of Personality Assessment, 89(3), 230-246. https://doi.org/10.1080/00223890701629698

Marchesi, C., Ossola, P., Tonna, M., \& De Panfilis, C. (2014). The TAS-20 more likely measures negative affects rather than alexithymia itself in patients with major depression, panic disorder, eating disorders and substance use disorders. Comprehensive Psychiatry, 55(4), 972-978. https://doi.org/10.1016/j.comppsych.2013.12.008

Marcus, D. K., Hughes, K. T., \& Arnau, R. C. (2008). Health anxiety, rumination, and negative affect: A mediational analysis. Journal of Psychosomatic Research, 64(5), 495-501. https://doi.org/10.1016/j. jpsychores.2008.02.004

Mattila, A. K., Kronholm, E., Jula, A., Salminen, J. K., Koivisto, A. M., Mielonen, R. L., \& Joukamaa, M. (2008). Alexithymia and somatization 
in general population. Psychosomatic Medicine, 70(6), 716-722. https:// doi.org/10.1097/PSY.0b013e31816ffc39

Mattila, A. K., Saarni, S. I., Salminen, J. K., Huhtala, H., Sintonen, H., \& Joukamaa, M. (2009). Alexithymia and health-related quality of life in a general population. Psychosomatics, 50(1), 59-68. https://doi.org/ 10.1176/appi.psy.50.1.59

McLaughlin, K. A., \& Nolen-Hoeksema, S. (2011). Rumination as a transdiagnostic factor in depression and anxiety. Behaviour Research and Therapy, 49(3), 186-193. https://doi.org/10.1016/j.brat.2010.12.006

Millgram, Y., Joormann, J., Huppert, J. D., \& Tamir, M. (2015). Sad as a matter of choice? Emotion-regulation goals in depression. Psychological Science, 26(8), 1216-1228. https://doi.org/10.1177/ 0956797615583295

Nolen-Hoeksema, S. (1991). Responses to depression and their effects on the duration of depressive episodes. Journal of Abnormal Psychology, 100(4), 569-582.

Nolen-Hoeksema, S., Larson, J., \& Grayson, C. (1999). Explaining the gender difference in depressive symptoms. Journal of Personality and Social Psychology, 77(5), 1061-1072.

Nolen-Hoeksema, S., Stice, E., Wade, E., \& Bohon, C. (2007). Reciprocal relations between rumination and bulimic, substance abuse, and depressive symptoms in female adolescents. Journal of Abnormal Psychology, 116(1), 198-207. https://doi.org/10.1037/0021-843X.116.1.198

Noyes, R., Jr., Kathol, R. G., Fisher, M. M., Phillips, B. M., Suelzer, M. T., \& Woodman, C. L. (1994). Psychiatric comorbidity among patients with hypochondriasis. General Hospital Psychiatry, 16(2), 78-87.

Olatunji, B. O., Deacon, B. J., \& Abramowitz, J. S. (2009). Is hypochondriasis an anxiety disorder?. The British Journal of Psychiatry, 194(6), 481-482. https://doi.org/10.1192/bjp.bp.108.061085

Rief, W., Hiller, W., \& Heuser, J. (1997). SOMS, das Screening für Somatoforme Störungen: Manual zum Fragebogen. Bern; Göttingen; Toronto; Seattle: Huber.

Rief, W., Ihle, D., \& Pilger, F. (2003). A new approach to assess illness behaviour. Journal of Psychosomatic Research, 54(5), 405-414.

Rief, W., Martin, A., Klaiberg, A., \& Brahler, E. (2005). Specific effects of depression, panic, and somatic symptoms on illness behavior. Psychosomatic Medicine, 67(4), 596-601. https://doi.org/10.1097/01. psy.0000171158.59706.e7

Saariaho, A. S., Saariaho, T. H., Mattila, A. K., Karukivi, M. R., \& Joukamaa, M. I. (2013). Alexithymia and depression in a chronic pain patient sample. General Hospital Psychiatry, 35(3), 239-245. https://doi.org/ 10.1016/j.genhosppsych.2012.11.011

Salkovskis, P. M., Rimes, K. A., Warwick, H. M., \& Clark, D. M. (2002). The Health Anxiety Inventory: Development and validation of scales for the measurement of health anxiety and hypochondriasis. Psychological Medicine, 32(5), 843-853.

Sheppes, G., Suri, G., \& Gross, J. J. (2015). Emotion regulation and psychopathology. Annual Review of Clinical Psychology, 11, 379-405. https://doi.org/10.1146/annurev-clinpsy-032814-112739

Shibata, M., Ninomiya, T., Jensen, M. P., Anno, K., Yonemoto, K., Makino, S., ... Hosoi, M. (2014). Alexithymia is associated with greater risk of chronic pain and negative affect and with lower life satisfaction in a general population: The Hisayama study. PloS One, 9(3), e90984. https://doi.org/10.1371/journal.pone.0090984
Sifneos, P. E. (1988). Alexithymia and its relationship to hemispheric specialization, affect, and creativity. The Psychiatric Clinics of North America, 11(3), 287-292.

Spitzer, R. L., Williams, J. B., \& Kroenke, K. (1999). Prime MD Today. Evaluation of Mental Disorders. Manual. USA: Pfizer US.

Taylor, G. J. (2000). Recent developments in alexithymia theory and research. The Canadian Journal of Psychiatry, 45(2), 134-142.

Taylor, G. J., \& Bagby, R. M. (2004). New trends in alexithymia research. Psychotherapy and Psychosomatics, 73(2), 68-77. https://doi.org/ 10.1159/000075537

Taylor, G. J., Bagby, R. M., \& Parker, J. D. (2003). The 20-item Toronto Alexithymia Scale. IV. Reliability and factorial validity in different languages and cultures. Journal of Psychosomatic Research, 55(3), 277-283.

Tominaga, T., Choi, H., Nagoshi, Y., Wada, Y., \& Fukui, K. (2014). Relationship between alexithymia and coping strategies in patients with somatoform disorder. Neuropsychiatric Disease and Treatment, 10, 55-62. https://doi.org/10.2147/NDT.S55956

Warwick, H. M., \& Salkovskis, P. M. (1990). Hypochondriasis. Behaviour Research and Therapy, 28(2), 105-117.

Watson, D., Clark, L. A., \& Tellegen, A. (1988). Development and validation of brief measures of positive and negative affect: The PANAS scales. Journal of Personality and Social Psychology, 54(6), 1063.

Wearden, A., Cook, L., \& Vaughan-Jones, J. (2003). Adult attachment, alexithymia, symptom reporting, and health-related coping. Journal of Psychosomatic Research, 55(4), 341-347.

Williams, P. (2004). The psychopathology of self-assessed health: A cognitive approach to health anxiety and hypochondriasis. Cognitive Therapy and Research, 28(5), 629-644.

Witthöft, M., Mier, D., Ofer, J., Muller, T., Rist, F., Kirsch, P., ... Diener, C. (2013). Neuronal and behavioral correlates of health anxiety: Results of an illness-related emotional Stroop task. Neuropsychobiology, 67(2), 93-102. https://doi.org/10.1159/000345545

Witthöft, M., Kerstner, T., Ofer, J., Mier, D., Rist, F., Diener, C., \& Bailer, J. (2016). Cognitive biases in pathological health anxiety: The contribution of attention, memory, and evaluation processes. 4(464-479), 2167702615593474

Yalug, I., Selekler, M., Erdogan, A., Kutlu, A., Dundar, G., Ankarali, H., \& Aker, T. (2010). Correlations between alexithymia and pain severity, depression, and anxiety among patients with chronic and episodic migraine. Psychiatry and Clinical Neurosciences, 64(3), 231-238. https://doi.org/10.1111/j.1440-1819.2010.02093.x

Zunhammer, M., Eberle, H., Eichhammer, P., \& Busch, V. (2013). Somatic symptoms evoked by exam stress in university students: The role of alexithymia, neuroticism, anxiety and depression. PloS One, 8(12), e84911. https://doi.org/10.1371/journal.pone.0084911 